\title{
Effect of gradation and fineness on performance of rubber asphalt mixture at low temperature
}

\author{
Haining Zhang ${ }^{1, a}$, Xuesong Mao ${ }^{1, b}$, Wenlin $\mathrm{Li}^{1}$ and Junfang $\mathrm{Gou}^{2}$ \\ ${ }^{1}$ Key Laboratory for Special Area Highway Engineering Ministry of Education, Chang'an University, \\ Xi'an 710064, China; \\ ${ }^{2}$ School of highway, Chang'an University, Xi'an 710064, China; \\ ashuimumu0808@hotmail.com, ${ }^{b}$ xuesongxian@aliyun.com
}

Keywords: Rubber asphalt mixture, Failure strain, Fineness, Gradation.

\begin{abstract}
Bending test of rubber asphalt mixture was studied, This paper selected 5 groups with different aggregate gradation, to figure out rubber asphalt mix properties at low temperature. A comprehensive indicator was considered by comparing the test results, included flexural tensile strength, failure strain, bending stiffness modulus index. In reference to the results of test, the rubber asphalt mixture with the median grade was recommended. On the basis, more experimental research was conducted further. In view of the available situation, the small beam bend test at low temperature was carried out, consisted of 20 mesh and 40 mesh rubber powder respectively. Our findings demonstrate that at the same level of asphalt-aggregate ratio and gradation, the 40 mesh rubber asphalt mixture has better performance at low temperature.
\end{abstract}

\section{Introduction}

Asphalt mixture cracking at low temperature brought a variety of diseases on asphalt pavement, asphalt pavement, especially in temperature decreasing abrupt or large temperature difference region, due to the effects of temperature and stress, asphalt pavement caused various cracks, which did serious harm to the life and quality of the road. For the sake of crack reduction on asphalt pavement, domestic and overseas scholars had taken up large-scale research on rubber additives in asphalt mixture. According to test data from trial pavement section, we found that the addition of rubber particles could improve low temperature performance of the road significantly, and reduce the occurrence of crazes. However, with technology development, numerous experimental facts showed rubber asphalt mixture low temperature properties related to not only cementing materials but also rubber fitness and gradation closely.

Based on the analysis of rubber asphalt mixture low temperature cracking mechanism, the article adopted low temperature failure strain, flexural tensile strength and stiffness modulus as the indexes in the performance evaluation of rubber asphalt mixture at low temperatures, rational gradation for rubber asphalt was given through test and analysis, and took this as a base, effect of rubber fitness on asphalt mixture performance at low temperature was probed into.

\section{Experimental}

\section{Materials}

Select 90\# petroleum asphalt was from Pinjin, which with needle penetration of $\left(25^{\circ} \mathrm{C}, 5 \mathrm{~S}, 100 \mathrm{~g}\right)$ 85.57, softening point of $50.6^{\circ} \mathrm{C}$, and density of $1.009 \mathrm{~g} / \mathrm{cm}^{3}$. The scrap rubber particle of 4 mesh ranged in size from 2.36 to $4.75 \mathrm{~mm}$, with apparent density of $1.18 \mathrm{~g} / \mathrm{cm}^{3}, 20$ mesh particle ranged from 0.15 to $0.6 \mathrm{~mm}$, with apparent density of $1.21 \mathrm{~g} / \mathrm{cm}^{3}, 40$ mesh particle ranged from 0.15 to $0.3 \mathrm{~mm}$, with apparent density of $1.21 \mathrm{~g} / \mathrm{cm}^{3}$, Basalt gravel aggregate content's apparent relative density were given in table 1 below, mineral powder as fillers was demanded without agglomeration apparent. 
Table 1 Relative density

\begin{tabular}{|c|c|c|c|c|}
\hline Sieve size (mm) & $0-3$ & $5-10$ & $10-20$ & Mineral powder \\
\hline Apparent relative density $(\mathrm{g} / \mathrm{cm} 3)$ & 2.774 & 2.805 & 2.803 & 2.705 \\
\hline Bulk volume relative desity $\left(\mathrm{g} / \mathrm{cm}^{3}\right)$ & 2.640 & 2.746 & 2.776 & 2.705 \\
\hline
\end{tabular}

\section{Mix design}

Reference to the relevant literature, continuous gradation asphalt mixture with AC-16 was selected, rubber granule of (volume fraction) 4\%, to form a flat type S grading curve. When the gradation was adjusted, proportion of coarse aggregates closing to maximum grain size and fine aggregates were reduced appropriately, coarse aggregates of middle (e.g. $5 \sim 10 \mathrm{~mm}, 10 \sim 20 \mathrm{~mm}$ ) were increased. Five series (the 1, 3, 5 represented upper limit, median, and lower limit respectively, the 2 was between upper limit and median, the 4 was between lower limit and median.) of AC-16 gradation were showed in Fig.1

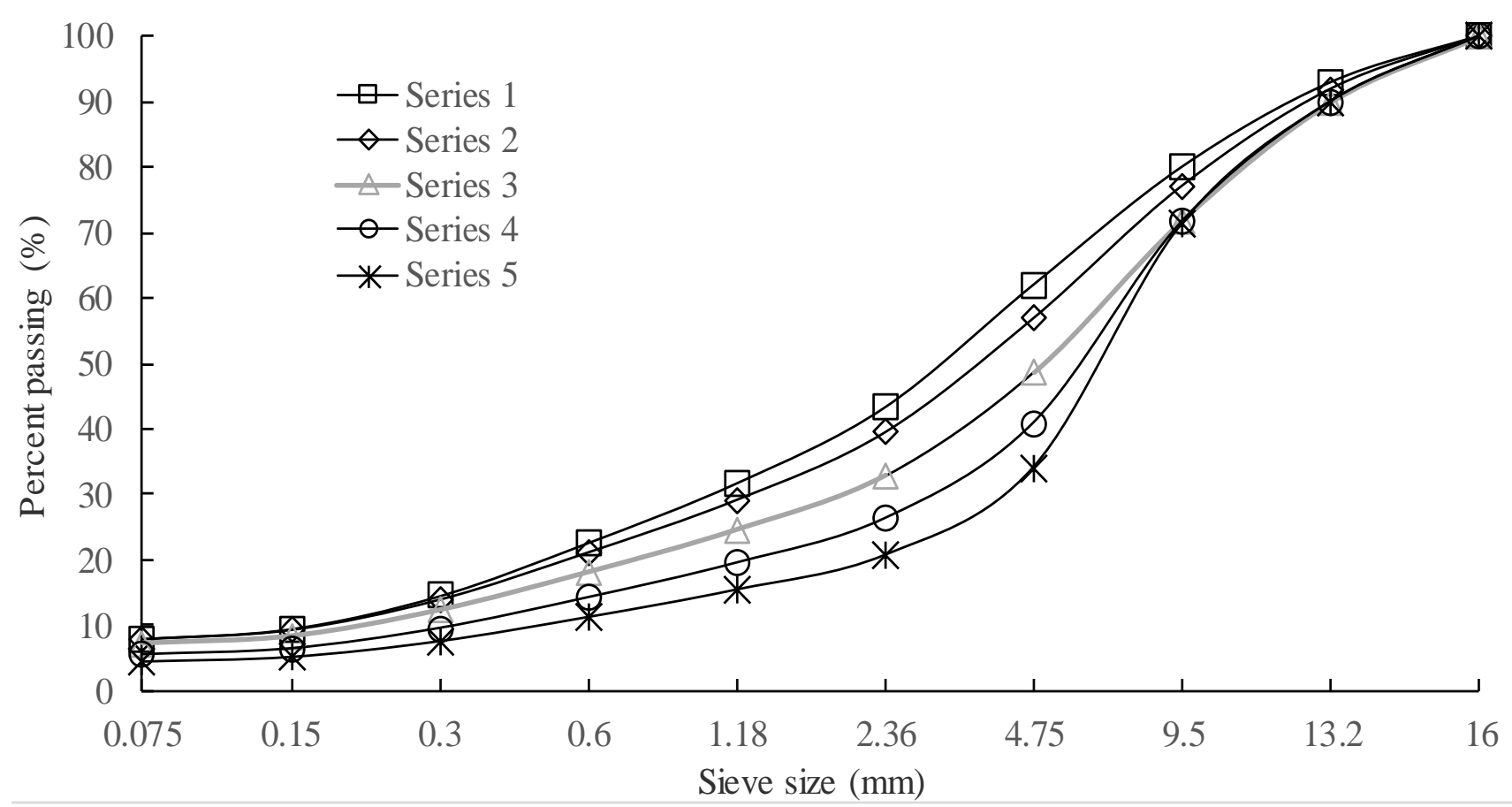

Fig. 1 Aggregate gradation

Table 2 showed that gradation rubber asphalt mixture with the type of the corresponding optimum asphalt content, which generated by computation method.

Table 2 Optimum asphalt content

\begin{tabular}{|c|c|c|c|c|c|}
\hline Series & 1 & 2 & 3 & 4 & 5 \\
\hline Optimum asphalt content (\%) & 4.67 & 4.64 & 4.57 & 4.53 & 4.49 \\
\hline
\end{tabular}

\section{Low temperature bend experiment}

In this paper, track plate with different gradations of $300 \mathrm{~mm} \times 350 \mathrm{~mm} \times 250 \mathrm{~mm}$, was rolled by LCX-2 asphalt mixture hydraulic wheel mill, then cut into small prismatic beam of $250 \mathrm{~mm} \pm 2 \mathrm{~mm}$ (length), $30 \mathrm{~mm} \pm 2 \mathrm{~mm}$ (width), $35 \mathrm{~mm} \pm 2 \mathrm{~mm}$ (height). The temperature was set at $-10{ }^{\circ} \mathrm{C}$, whereas loading rate was $50 \mathrm{~mm} / \mathrm{min}$.

\section{Results and analysis}

Mineral aggregate was skeleton and main body of rubber asphalt mixture. Different asphalt content, particles size and distribution, and gradations affected a series of characters of asphalt mixture. Considering rubber asphalt mixture properties at low temperature. 5 series of gradations of rubber asphalt mixture test results were given in below from Fig. 2 to Fig. 4. 


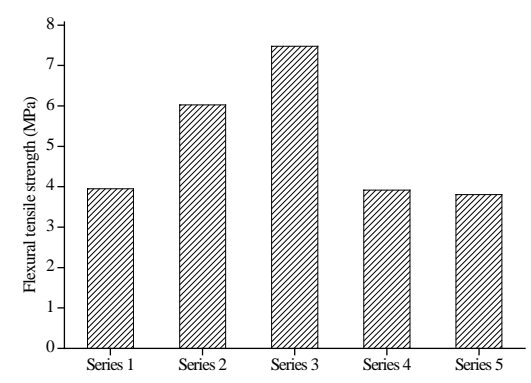

Fig. 2 Flexural tensile strength of different series

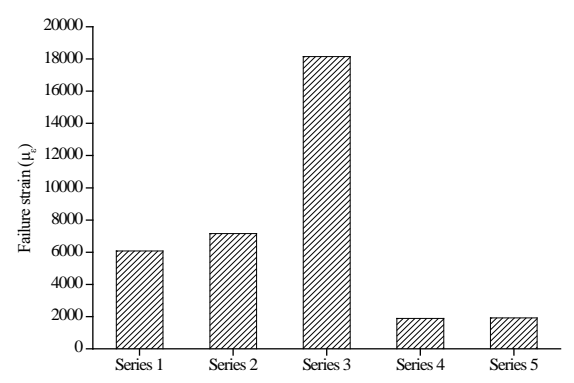

Fig. 3 Failure strain of different series

From Fig.2, flexural tensile strength was listed in descending order: series $3>$ series $2>$ series $1>$ series $4>$ series 5, with the overall trend of going up firstly and going down secondly, the series 3 was as a dividing line. In other words, the flexural tensile strength of median gradation reached the maximum. As Fig.3 showed that failure strain of different series had a similar regulation, there was a slight difference that series 5 had higher value than series 4 .

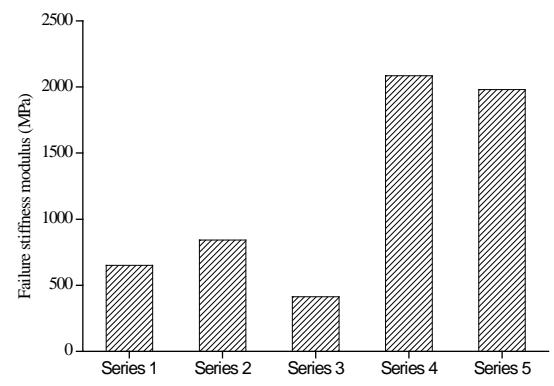

Fig. 4 Failure stiffness modulus of different series

There was another matter entirely, to the two figures above, Fig.4 revealed almost the opposite result. The datum was sorted by descending order: series $5>$ series $2>$ series $4>$ series $1>$ series 3 . The two series adjoined to lower limit possessed higher values than others.

In conclusion, series 3 was higher than the other series, when selecting flexural tensile strength and failure strain as evaluation indexes, and had lower failure stiffness modulus. Due to the grading curve of series 3 was more close to a flat $\mathrm{S}$ type. Considering relationship between evaluation index and rubber asphalt mixture at low temperature performance, we can conclude that series 3 had better property at low temperature. Herein, follow up low-temperature bend experiment were performed based on gradation of series 3 rubber asphalt mixture.

Table 3 Test results

\begin{tabular}{|c|c|c|c|}
\hline Fitness & Flexural tensile strength(MPa) & Failure strain $\left(\mu_{\varepsilon}\right)$ & Failure stiffness modulus(MPa) \\
\hline 20 mesh & 7.58 & 3301 & 393.5 \\
\hline 40 mesh & 9.20 & 3412 & 300.4 \\
\hline
\end{tabular}

As table 3 showed that 40 mesh rubber asphalt mixture had higher flexural tensile strength and failure strain value, and lower Failure stiffness modulus than 20 mesh asphalt mixture. Because of rubber powder mesh got bigger, the particle size got smaller. The larger contact area of rubber powder and asphalt, more asphalt oil easily absorbed by powder tended to expansion, the rubber 
asphalt mixture void fraction reached its optimal, the rubber powder and asphalt were easy to achieve better dispersion state.

\section{Summary and conclusions}

Series 3 rubber asphalt mixture has better properties at low temperature, according to three indexes revealed, as gradation curve was close to $\mathrm{S}$ type, had more advantages in practical. For different fitness of rubber asphalt mixture, the smaller particle fineness of rubber powder it was, the better the performance of asphalt mixture had at low temperature, the 40 mesh rubber powder asphalt mixture has good structure homogeneous and performance, which could maintain stability in a long time. 40 to recommend the use of rubber powder in asphalt rubber mixture, the use of 40 mesh powder was Recommended as incorporation for rubber asphalt mixture.

\section{Acknowledgements}

The financial support of National Science and Technology Support Programme Project (project number: 2014BAG05B00) and The Highway Construction Technology Promotes the Applied Research in Xinjiang Typical Alpine Permafrost Region (project number: 2011-318-365-100) to this investigation through research groups is kindly acknowledged.

\section{References}

[1] Jiazhu Wang, Shaopeng Wu. Design of skeletal dense structure for asphalt mixture. Journal of Highway and Transportation Research and Development. Vol. 23 (2006) No. 11, p. 31-35.

[2] Rongji Cao, Rongsheng Chen. Laboratory study on process parameters of asphalt rubber and their effects on performance. Southeast University Journal: Natural Science. Vol. 38 (2008) No. 2, p. 269-275.

[3] Yue Huang, Roger N. Bird, Oliver Heidrich. A review of the use of recycled solid waste materials in asphalt pavements. Resources, Conservation and Recycling. Vol. 52 (2007) No. 1, p. 58-73.

[4] Zhengqi Zhang, Zhanli Zhao, Weiping Zhang. Effect of Aggregate Gradation on Performance of Asphalt Mix at Low Temperature. Journal of Chang' an University: Natural Science Edition. Vol. 25 (2005) No. 1, p. 1-5.

[5] Jamrah, Anas, M. Emin Kutay, Sudhir Varma. Backcalculation of Swollen Crumb Rubber Modulus in Asphalt Rubber Binder and Its Relation to Performance. Transportation Research Record: Journal of the Transportation Research Board Vol. 2505 (2015) No. 13, p. 99-107. 